\title{
Association between plasma homocysteine levels and pancreatic islet beta-cell function in the patients with type 2 diabetes mellitus: a cross-sectional study from China
}

\author{
Xinlu Yuan ${ }^{1,2 \#}$, Sheng Ding ${ }^{3 \#}$, Ligang Zhou $^{1}$, Song Wen ${ }^{1}$, Anqing Du ${ }^{4 \#}$, Jianjun Diao $^{5 *}$ \\ ${ }^{1}$ Department of Endocrinology and Metabolic Diseases, Shanghai Pudong Hospital, Fudan University Pudong Medical Center, Shanghai, China; \\ ${ }^{2}$ Department of Endocrinology and Metabolic Diseases, Affiliated Hospital of Nantong University, Nantong, China; ${ }^{3}$ Department of Endocrinology, \\ The Central Hospital of Wuhan, Tongji Medical College, Huazhong University of Science and Technology, Wuhan, China; ${ }^{4}$ Department of \\ Stomatology, Shanghai Pudong Hospital, Fudan University Pudong Medical Center, Shanghai, China; ${ }^{5}$ Department of Emergency, Shanghai Pudong \\ Hospital, Fudan University Pudong Medical Center, Shanghai, China \\ Contributions: (I) Conception and design: X Yuan, A Du; (II) Administrative support: L Zhou, J Diao; (III) Provision of study materials or patients: S \\ Ding; (IV) Collection and assembly of data: S Wen; (V) Data analysis and interpretation: S Wen, X Yuan; (VI) Manuscript writing: All authors; (VII) \\ Final approval of manuscript: All authors. \\ \#These authors contributed equally to this work. \\ Correspondence to: Jianjun Diao. Department of Emergency, Shanghai Pudong Hospital, Fudan University Pudong Medical Center, 2800 Gongwei \\ Road, Pudong, Shanghai 201399, China. Email: 49223882@qq.com; Anqing Du. Department of Stomatology, Shanghai Pudong Hospital, Fudan \\ University Pudong Medical Center, 2800 Gongwei Road, Pudong, Shanghai 201399, China. Email: 912521736@qq.com.
}

Background This study sought to investigate the association between plasma homocysteine (HCY) levels and pancreatic islet beta-cell function in type 2 diabetes mellitus (T2DM) patients.

Methods: 430 hospitalized T2DM patients were enrolled in this cross-sectional study from December 2013 to December 2016. All participants were requested to complete a detailed questionnaire and undergo anthropometric measurements. Blood samples were collected from all participants. A 75 -g oral glucose tolerance test (OGTT) was performed to diagnose T2DM in each individual, and an insulin releasing test (IRT) was used to calculate selected parameters for glucose, insulin, and C-peptide. Linear correlation and multivariate regression analyses were performed to assess the association between serum HCY concentration and these parameters.

Results: Patients were divided into the following subgroups based on quartiles of serum HCY levels: Group Q1: <17.03 $\mu \mathrm{mol} / \mathrm{L}$; Group Q2: 17.03-19.50 $\mu \mathrm{mol} / \mathrm{L}$; Group Q3: 19.5-24.7 $\mu \mathrm{mol} / \mathrm{L}$; and Group Q4: $>24.7 \mu \mathrm{mol} / \mathrm{L}$. The levels of fasting blood glucose (FBG), $2 \mathrm{~h}$ postprandial blood glucose (2hPBG), glycated hemoglobin A1c (HbA1c), fasting C-peptide and fasting insulin increased significantly as HCY levels increased $(\mathrm{P}<0.05)$. The area under the curves (AUCs) of serum glucose and insulin in IRT increased significantly and that of serum $\mathrm{C}$-peptide decreased as HCY levels increased $(\mathrm{P}<0.05)$. The levels of Homeostasis Model Assessment- $\beta$ (HOMA- $\beta$ ), Modified Beta-cell function Index (MBCI), Disposal Index (DI), C-peptide immunoreactivity (CPR), Insulinogenic Index 30 (IGI 30), and Secretory Units of Islets in Transplantation (SUIT) decreased as HCY levels increased. An inverse linear correlation was found between HOMA- $\beta$, MBCI, DI, CPR, IGI 30, SUIT 0 h, and HCY plasma concentration $\left(\mathrm{R}^{2}, 0.539,0.569,0.500\right.$, $0.676,0.579$, and 0.588 , respectively; $\mathrm{P}<0.001$ ), and this association was independent of many confounders, such as age, gender, body mass index, glucose and insulin levels, and HbAlc.

Conclusions: Serum HCY levels were inversely related to the parameters for pancreatic islet beta-cell function. Thus, the insulin releasing function of beta cells in the pancreas can be well elucidated by plasma HCY concentration.

Keywords: Type 2 diabetes mellitus (T2DM); homocysteine; pancreatic islet $\beta$-cells function; Homeostasis Model Assessment- $\beta$ (HOMA- $\beta$ ) 
Submitted Jun 07, 2021. Accepted for publication Jul 13, 2021.

doi: 10.21037/apm-21-1671

View this article at: https://dx.doi.org/10.21037/apm-21-1671

\section{Introduction}

Type 2 diabetes mellitus (T2DM), which is defined as the phenotype of hyperglycemia, is a growing health problem worldwide (1). More than $11.6 \%$ individuals in the Chinese adult population and 420 million people globally suffer from diabetes, and it will reach a global prevalence of 642 million by $2040(2,3)$. Further, more than $90 \%$ of diabetic patients in China suffer from T2DM. The accelerating prevalence of diabetes will inevitably result in the increasing occurrence of diabetic complications, such as retinopathy and neuropathy, which have high financial costs to both the individual and society.

In addition to insulin resistance, the impaired insulin secretion of pancreatic islet beta-cells also plays a pivotal role in the pathogenesis of T2DM (4). In daily practice, oral glucose tolerance tests (OGTTs) are used to diagnose diabetes, and plasma glucose and glycated hemoglobin A1c (HbA1c) levels are used to evaluate glycemic control in T2DM patients. These data are easily accessible, but do not accurately reflect pancreatic function (5). The hyperglycemic clamp is considered the gold-standard method for evaluating insulin secretion; however, it is both inconvenient and invasive (6). Thus, it is necessary to find serological biomarkers to evaluate beta-cell function, as such markers will be valuable tools for the early diagnosis, prognosis, and tailoring of treatments for T2DM in the future.

Over the past decade, plasma homocysteine (HCY), a sulfur containing a non-protein amino acid that is involved in the metabolism of methionine, has attracted much attention. It has been reported to be an independent risk factor or marker of neural system disorders, such as Alzheimer's disease, and cardiovascular diseases, such as atherosclerosis (7-9). The reason for its occurrence may be the pathogenesis of cardiovascular structures and endothelial dysfunctions induced by hyperhomocysteinemia. Recently, several studies identified an association between diabetes and HCY. Notably, one study showed that serum $\mathrm{HCY}$ concentration is elevated in T2DM patients, and is associated with vascular complications (10), and another study showed that elevated HCY levels are associated with insulin resistance in patients with T2DM (11). Similar results were shown on Diabetes Care that insulin resistance and renal function are independent determinants of HCY level in type 2 diabetes patients.

However, to date, very few studies have investigated the relationship between serum HCY levels and impaired pancreatic islet beta-cell function in T2DM patients. Thus, to test the hypothesis that high HCY levels are related to the insulin releasing ability of pancreatic islet beta cells in T2DM patients, we calculated indexes relevant to the insulin secretion of pancreatic beta cells in $430 \mathrm{~T} 2 \mathrm{DM}$ patients, and investigated the correlations between these indexes and serum HCY levels.

We present the following article in accordance with the STROBE reporting checklist (available at https://dx.doi. org/10.21037/apm-21-1671).

\section{Methods}

\section{Subjects}

A total of 430 participants from the Endocrinology Department were enrolled in this cross-sectional study from December 2013 to December 2016. This study was conducted in accordance with the principles of the Declaration of Helsinki (as revised in 2013). This study was approved by ethics board of Shanghai Pudong Hospital (No.: wz-009). Informed consent was obtained from all individual participants included in the study.

To be eligible to participate in this study, patients had to be aged over 18 years and have been diagnosed with T2DM, which was defined by the World Health Organization as a fasting plasma glucose concentration $\geq 126 \mathrm{mg} / \mathrm{dL}$ or a 2 -h OGTT value $\geq 200 \mathrm{mg} / \mathrm{dL}$ (12). Patients were excluded from the study if they met any of the following exclusion criteria: (I) had type1 diabetes or other special types of diabetes; (II) had a severe infection; (III) had hypercortisolism (Cushing's syndrome), growth hormone syndrome, or thyroid dysfunction; (IV) had a cardiovascular disease, chronic lung disease, cancer (in the last 5 years), kidney failure (or were undergoing dialysis), had received a transplant, had undergone recent major surgery, had a seizure disorder or epilepsy; (V) were pregnant or lactating females; (VI) were unable to give 
informed consent; and/or (VII) had a vitamin B12, folate, or methylenetetrahydrofolate reductase deficiency.

\section{Clinical and laboratory examinations}

Measurements of height, weight, waist circumference, and blood pressure were taken for each patient according to standard procedures by an experienced staff member. Body mass index (BMI; $\mathrm{kg} / \mathrm{m}^{2}$ ) was calculated as body weight $(\mathrm{kg}) /$ height ${ }^{2}\left(\mathrm{~m}^{2}\right)$. Waist-to-height ratio (WHR) was calculated as waist/height. Venous blood was obtained early in the morning after overnight fasting. Plasma glucose levels were analyzed using the hexokinase/kinetic method. Serum insulin and C-peptide were measured by a two-sited, time-resolved fluor immunoassay (Auto DELFIA Insulin kit, Wallac Oy, Turku, Finland). Glycosylated hemoglobin (HbA1c) was measured using Tosoh Automated Glycohemoglobin Analyzer HLC723G8 (Tosoh Corporation, Tokyo, Japan). Total cholesterol (TC), triglycerides (TG), high-density lipoprotein cholesterol (HDL-C), and low-density lipoprotein cholesterol (LDL-C) were measured by an enzymatic colorimetric test (Roche Modular systems). Serum uric acid (UA) and HCY were determined by immunoassays (enzymatic method, Roche Life Science, US). The assay was carried out in accordance with the manufacturer's instructions.

\section{Insulin releasing test and beta-cell function modeling}

After overnight fasting, an IRT was performed with sampling before (time 0 ) and 30, 60, 90, 120, and $180 \mathrm{~min}$ after the ingestion of $100 \mathrm{~g}$ steamed bun, which was equal to $75 \mathrm{~g}$ of glucose. Serum glucose, insulin, and C-peptide concentration were measured. Participants who injected insulin stopped injections 3 days before the test. Many indexes were calculated from the plasma glucose and insulin levels of the IRT. The following parameters were calculated: Homeostasis Model Assessment- $\beta$ (HOMA- $\beta$ ), $20 \times$ FINS $(\mu \mathrm{g} / \mathrm{L}) /[$ fasting blood glucose $(\mathrm{FBG})(\mathrm{mmol} / \mathrm{L})$ -3.5] (13); Modified Beta-cell function Index (MBCI), FINS $(\mu \mathrm{g} / \mathrm{L}) \times$ FBG $(\mathrm{mmol} / \mathrm{L}) /(2 \mathrm{~h}$ postprandial blood glucose $(2 \mathrm{~h} \mathrm{PBG})(\mathrm{mmol} / \mathrm{L})+1 \mathrm{~h} \mathrm{PBG}(\mathrm{mmol} / \mathrm{L})-2 \times$ FBG (mmol/L) (14); Insulinogenic Index 30 (IGI30), [0.5 h FINS $(\mu \mathrm{g} / \mathrm{L})-$ FINS $(\mu \mathrm{g} / \mathrm{L})] /[0.5 \mathrm{~h} \mathrm{PBG}(\mathrm{mmol} / \mathrm{L})$ - FBG (mmol/L)] (15); Disposal Index (DI), IGI/HOMAIR; Secretory Units of Islets in Transplantation (SUIT), C-peptide $(\mu \mathrm{g} / \mathrm{L}) \times 1485 /[\mathrm{FBG}(\mathrm{mg} / \mathrm{dL})-61.8](16,17)$; C-peptide Immunoreactivity (CPR); C-peptide $(\mu \mathrm{g} / \mathrm{L})$ $\times$ 100/FBG $(\mathrm{mg} / \mathrm{dL})(18)$.

\section{Statistical analysis}

SPSS17.0 (IBM, USA) was used for the statistical analysis. The continuous data are presented as means \pm standard deviations (SDs). Comparisons between multiple groups were performed using an analysis of variance. Intergroup comparisons were performed using $t$ tests. Correlations between HCY and the parameters were calculated using Pearson and Spearman tests. Multiple linear-regression analyses (unadjusted and adjusted for all confounders) were performed to assess the association between $\mathrm{HCY}$ and the parameters. A $\mathrm{P}<0.05$ was considered statistically significant.

\section{Results}

In this study, 59.5\% [256] of participants were male, and $40.5 \%$ [174] were female. Patients had a mean age of $57.19 \pm 10.70$ (range, $41-87$ years). To ensure an even distribution across the groups, the patients were divided into the following subgroups using HCY quartiles: Group Q1: $<17.03 \mu \mathrm{mol} / \mathrm{L}$; Group Q2: 17.03-19.50 $\mu \mathrm{mol} / \mathrm{L}$; Group Q3: 19.5-24.7 $\mu \mathrm{mol} / \mathrm{L}$; and Group Q4: >24.7 $\mu \mathrm{mol} / \mathrm{L}$. There were older and more male participants in the higher quartile. Additionally, weight, waist, waist/height, FBG, 2hPBG, HbA1c, fasting C-peptide, fasting insulin, total cholesterol, triglycerides, LDL-C, and uric acid levels increased significantly as levels of HCY increased $(\mathrm{P}<0.05)$. Conversely, the HDL-C levels decreased significantly as HCY levels increased $(\mathrm{P}<0.05)$. No significant differences were observed in patients' heights and BMIs between the groups $(\mathrm{P}>0.05)$. The above-mentioned data are presented in Table 1 .

\section{Comparison of serum glucose, insulin and C-peptide among groups}

The IRT results of each subgroup are shown in Figure 1. The serum glucose level of participants in Group Q4 was significantly higher than the serum glucose levels of participants in the other three groups during the test (at $90,120$, and $180 \mathrm{~min} ; \mathrm{P}<0.05)$. The serum glucose levels of participants in Groups Q2 and Q3 were similar, and were higher than those of the $\mathrm{Q} 1$ group $(\mathrm{P}<0.05)$. Participants' serum insulin levels were significantly elevated and the difference between participants in Group Q4 and those in the other three groups was statistically significant except at time $0(\mathrm{P}<0.05)$. In addition, participants in Group $\mathrm{Q} 4 \mathrm{had}$ lower serum C-peptide levels than those in the other three 
Table 1 Baseline characteristics of all participants stratified by homocysteine quartiles

\begin{tabular}{|c|c|c|c|c|}
\hline Variables & \multicolumn{4}{|c|}{ Quartiles of $\mathrm{HCY}, \mu \mathrm{mol} / \mathrm{L}$} \\
\hline Median HCY, $\mu \mathrm{mol} / \mathrm{L}$ & $14.13 \pm 2.95$ & $18.60 \pm 0.67$ & $21.66 \pm 1.53$ & $27.72 \pm 2.51$ \\
\hline $\mathrm{N}$ & 110 & 109 & 103 & 108 \\
\hline Age, year & $42.87 \pm 11.87$ & $56.96 \pm 9.94$ & $60.41 \pm 10.55^{\star}$ & $68.53 \pm 10.44^{\star \#}$ \\
\hline Height, cm & $164.15 \pm 7.22$ & $164.29 \pm 8.31$ & $164.27 \pm 8.62$ & $166.43 \pm 7.98$ \\
\hline Weight, kg & $66.45 \pm 13.25$ & $67.44 \pm 14.58$ & $66.77 \pm 12.25$ & $69.55 \pm 11.72^{*}$ \\
\hline Waist, cm & $86.12 \pm 10.86$ & $89.87 \pm 10.85$ & $88.99 \pm 10.18$ & $91.08 \pm 10.00^{*}$ \\
\hline Waist/height & $0.52 \pm 0.06$ & $0.53 \pm 0.06$ & $0.54 \pm 0.06$ & $0.55 \pm 0.06^{\star \#}$ \\
\hline DBP, $\mathrm{mmHg}$ & $82.52 \pm 12.80$ & $72.51 \pm 20.14$ & $92.31 \pm 11.57^{\#}$ & $87.29 \pm 19.52^{\#}$ \\
\hline Fasting glucose, $\mathrm{mmol} / \mathrm{L}$ & $9.45 \pm 2.82$ & $9.30 \pm 2.89$ & $9.62 \pm 2.26$ & $10.01 \pm 2.62^{*}$ \\
\hline $2 \mathrm{~h}$ postprandial glucose, $\mathrm{mmol} / \mathrm{L}$ & $18.58 \pm 4.06$ & $18.85 \pm 4.82$ & $19.05 \pm 4.45$ & $19.23 \pm 4.07^{\star}$ \\
\hline $\mathrm{HbA} 1 \mathrm{c}, \%$ & $9.36 \pm 2.22$ & $9.48 \pm 2.35$ & $9.54 \pm 2.33^{*}$ & $10.12 \pm 2.45^{\star \#}$ \\
\hline Fasting C-peptide, $\mu \mathrm{g} / \mathrm{L}$ & $2.06 \pm 1.05$ & $2.06 \pm 1.17$ & $1.93 \pm 1.06$ & $1.87 \pm 1.14^{\star \#}$ \\
\hline Fasting serum insulin, mIU/L & $11.06 \pm 13.67$ & $13.96 \pm 12.56^{\star}$ & $13.77 \pm 10.37^{\star}$ & $20.12 \pm 13.39^{\text {*\#\& }}$ \\
\hline Total cholesterol, mg/dL & $4.84 \pm 1.70$ & $4.72 \pm 1.14$ & $5.13 \pm 1.42^{\star \#}$ & $5.01 \pm 1.15^{\#}$ \\
\hline Triglycerides, mg/dL & $1.61 \pm 1.44$ & $1.90 \pm 1.23$ & $2.26 \pm 1.54^{\star \#}$ & $2.71 \pm 2.04^{\star \# \&}$ \\
\hline
\end{tabular}

Variables are presented as mean \pm standard deviation. *, $\mathrm{P}<0.05$ vs. Q1; *, $\mathrm{P}<0.05$ vs. Q2; ${ }^{*}, \mathrm{P}<0.05$ vs. Q3. SBP, systolic blood pressure; DBP, diastolic blood pressure; HDL-C, high-density lipoprotein cholesterol; LDL-C, low-density lipoprotein cholesterol; HCY, homocysteine; BMI, body mass index.

groups. In sum, the area under the curves (AUCs) of serum glucose and insulin in Group Q4 were higher than those of the other 3 groups (glucose: $50.70 \pm 3.12$ vs. $46.80 \pm 3.16$, $48.50 \pm 3.29$, and $49.40 \pm 2.00$, and insulin: $136.47 \pm 16.13 v s$. $73.92 \pm 10.40,96.69 \pm 13.17$, and $103.00 \pm 10.73$, respectively) while the AUC of C-peptide in Group Q4 was lower than the AUCs of Groups Q1-Q3 (10.98 \pm 2.93 vs. 13.02 \pm 3.06 , $12.27 \pm 3.84$, and $12.00 \pm 3.00$, respectively).

\section{Parameters calculated from IRT differs between groups}

According to the above results, many parameters can be calculated to evaluate the insulin releasing function of pancreatic beta cells (i.e., HOMA- $\beta$, MBCI, DI, CPR, IGI 30, and SUIT). Changes in HOMA- $\beta$ levels were significantly different between the four groups. MBC, CPR, and IGI 30 levels in Group Q4 were lower than those of the other three groups $(\mathrm{P}<0.05)$. Additionally, DI and SUIT levels decreased as HCY levels increased, and in Group Q4, DI declined by 52\% compared to that of Group $\mathrm{Q} 1(\mathrm{P}<0.05)$. Additionally, the difference of SUIT levels between the Q1 and Q4 group appeared from the basal line to $1 \mathrm{~h}$ and disappeared at 2 and $3 \mathrm{~h}$ after energy intake. The SUIT levels at $2 \mathrm{~h}$ of Group Q3 were lower than those of Group Q1, and the SUIT levels at $3 \mathrm{~h}$ of Group Q4 were lower than those of Groups Q2 and Q3 $(\mathrm{P}<0.05)$. These 
$A_{1}$

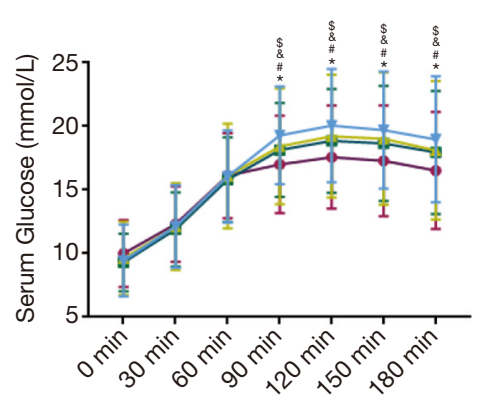

$B_{1}$

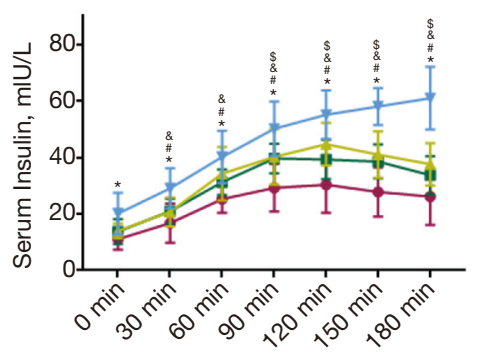

$C_{1}$

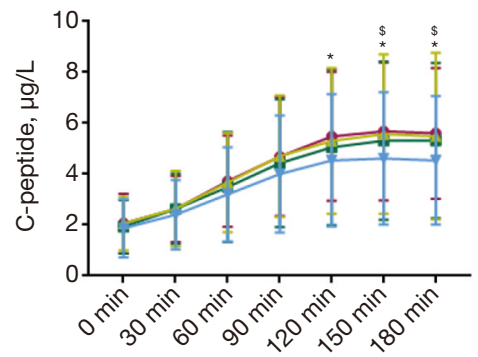

$\mathrm{A}_{2}$ $\rightarrow$ Q1

$-Q_{2}$

$₫ \mathrm{Q} 3$

* Q4

$\rightarrow$ Q1
$\rightarrow$ Q 2

$\rightarrow \mathrm{Q} 3$

+ Q4

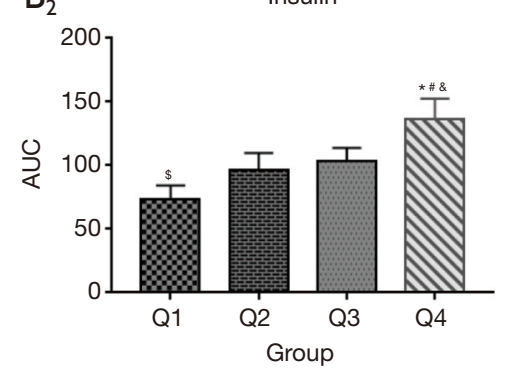

$\mathrm{C}_{2}$

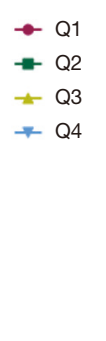

$\mathrm{B}_{2}$

Glucose

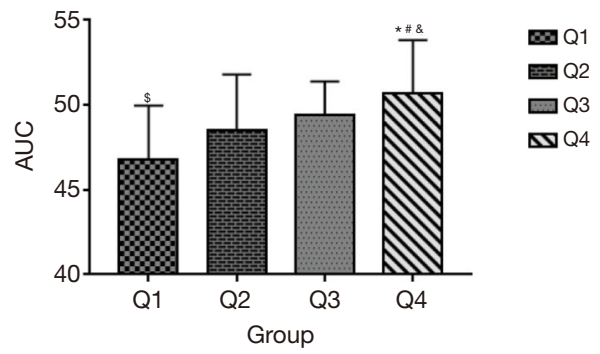

$\operatorname{BO} \mathrm{Q} 1$

푸몰 Q2

Q3

$\square \mathrm{Q4}$

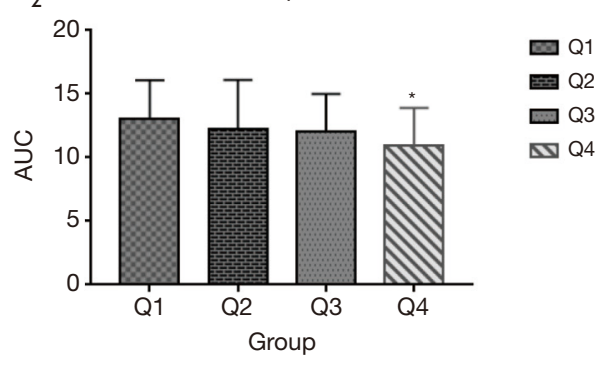

Figure 1 Glucose metabolism of participants in each group. $\left(A_{1}\right)$ Serum glucose curves and $\left(A_{2}\right)$ their AUCs; $\left(B_{1}\right)$ serum insulin curves, and $\left(B_{2}\right)$ their AUCs; $\left(\mathrm{C}_{1}\right) \mathrm{C}$-peptide curves and $\left(\mathrm{C}_{2}\right)$ their AUCs. *, $\mathrm{P}<0.05$ Q1 vs. Q4; ${ }^{*}, \mathrm{P}<0.05$ Q2 vs. Q4; ${ }^{\circledR}, \mathrm{P}<0.05$ Q3 vs. Q4; ${ }^{\circledR}, \mathrm{P}<0.05$ Q1 vs. Q2 and Q3. AUC, area under the curve.

data are presented in Table 2.

We performed linear correlation analyses to examine the relationships between serum HCY levels and the parameters. The results are shown in Figure 2. Negative correlations were found between HOMA- $\beta$, MBCI, DI, and HCY plasma concentration $\left(\mathrm{R}^{2}, 0.539,0.569\right.$, and 0.500 , respectively; $\mathrm{P}<0.000$ ). Additionally, CPR, IGI 30, and SUIT levels at $0 \mathrm{~h}$ were inversely and extensively related to HCY levels $\left(\mathrm{R}^{2}\right.$, $0.676,0.579$ and 0.588 , respectively; $\mathrm{P}<0.001$ ).

\section{Serum HCY level independently associated with parameters from IRT}

As Table 3 shows, multivariable regression analyses were carried out to determine whether serum HCY levels were independently associated with the parameters by adjusting for likely confounders. Model 1 was a univariate analysis. Model 2 was adjusted for age and gender. Model 3 was adjusted for age, gender, height, weight, waist, waist/ height, BMI, FBG, 2hPBG, HbA1c, fasting insulin, and C-peptide. In the multivariable linear-regression analysis, HCY was negatively correlated with MBCI and DI in all models. HCY had a significant relationship with HOMA- $\beta$ and SUIT at $0 \mathrm{~h}$ after adjusting for age, gender, and all confounders. HCY was inversely correlated with IGI 30 in Model 1; however, the correlation became statistically insignificant in Models 2 and 3. HCY was significantly negatively associated with CPR in the univariate analysis for 
Table 2 Parameters calculated from the OGTT results of all participants stratified by homocysteine quartiles

\begin{tabular}{|c|c|c|c|c|}
\hline Variables & \multicolumn{4}{|c|}{ Quartiles of HCY, $\mu \mathrm{mol} / \mathrm{L}$} \\
\hline HOMA- $\beta$ & $47.19 \pm 29.46$ & $41.91 \pm 22.92^{*}$ & $37.42 \pm 14.70^{\text {*\# }}$ & $36.16 \pm 16.17^{\star \# \&}$ \\
\hline $\mathrm{MBCl}$ & $3.72 \pm 0,94$ & $3.57 \pm 1.46$ & $3.47 \pm 0.60^{\star}$ & $3.41 \pm 0.60^{* \# \&}$ \\
\hline CPR index & $1.27 \pm 0.78$ & $1.27 \pm 0.76$ & $1.28 \pm 0.89$ & $1.14 \pm 0.80^{\text {*\#\& }}$ \\
\hline DI & $1.83 \pm 1.16$ & $1.16 \pm 2.23$ & $0.74 \pm 1.20^{*}$ & $0.88 \pm 1.71^{*}$ \\
\hline SUIT $0 \mathrm{~h}$ & $37.52 \pm 39.57$ & $33.47 \pm 24.62$ & $32.14 \pm 22.50^{\star}$ & $29.21 \pm 24.96^{*}$ \\
\hline SUIT $1 \mathrm{~h}$ & $30.13 \pm 36.08$ & $29.23 \pm 19.20$ & $27.34 \pm 20.88$ & $23.69 \pm 17.08^{\star \#}$ \\
\hline SUIT $2 \mathrm{~h}$ & $35.11 \pm 36.76$ & $33.24 \pm 26.22$ & $29.35 \pm 22.93^{*}$ & $32.57 \pm 22.23$ \\
\hline
\end{tabular}

Variables are presented as mean \pm standard deviation. *, $\mathrm{P}<0.05$ vs. Q1; " $\mathrm{P}<0.05$ vs. Q2; ${ }^{\circ}, \mathrm{P}<0.05$ vs. Q3. HOMA- $\beta$, Homeostasis Model Assessment- $\beta$; MBCI, Modified $\beta$ Cell Function Index; IGI 30, Insulinogenic Index 30; DI, Disposal Index; SUIT, Secretory Units of Islets in Transplantation; CPR, C-peptide immunoreactivity.
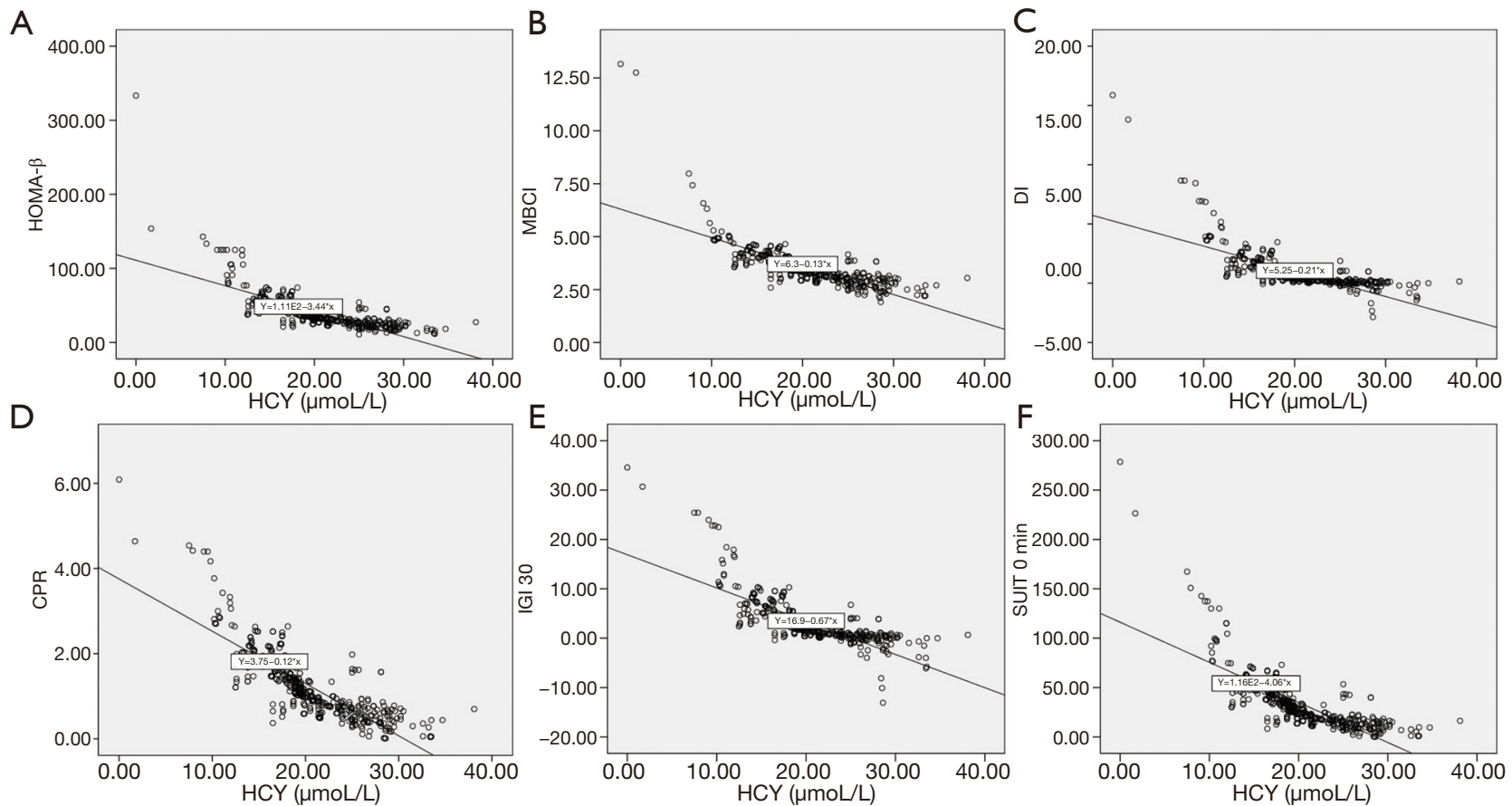

Figure 2 Liner correlation analysis of HCY levels and parameters related to pancreatic islet beta-cell function using the Pearson and Spearman test models. (A) HOMA- $\beta, \mathrm{R}^{2}=0.593$; (B) MBCI, $\mathrm{R}^{2}=0.569$; (C) DI, $\mathrm{R}^{2}=0.500$; (D) CPR, R²=0.676; (E) IGI 30, R²=0.579; (F) SUIT 0, $\mathrm{R}^{2}=0.588$. HOMA- $\beta$, Homeostasis Model Assessment- $\beta$; MBCI, Modified $\beta$-Cell Function Index; DI, Disposal Index; CPR, C-peptide Immunoreactivity; IGI 30, Insulinogenic Index 30; SUIT 0, Secretory Units of Islets in Transplantation 0. 
Table 3 Multivariate linear-regression analyses of the effects of HCY on parameters related to function of pancreatic beta cells

\begin{tabular}{|c|c|c|c|c|c|c|}
\hline Variables & \multicolumn{2}{|c|}{ Model 1} & \multicolumn{2}{|c|}{ Model 2} & \multicolumn{2}{|c|}{ Model 3} \\
\hline \multicolumn{7}{|l|}{ HOMA- $\beta$} \\
\hline $\mathrm{HCY}$ & $-0.021(0.036)$ & 0.554 & $-0.179(0.142)$ & 0.003 & $-0.279(0.099)$ & 0.005 \\
\hline $\mathrm{HCY}<15 \mu \mathrm{mol} / \mathrm{L}$ & ref & - & ref & - & ref & - \\
\hline \multicolumn{7}{|l|}{$\mathrm{MBCl}$} \\
\hline $\mathrm{HCY}$ & $-4.151(0.924)$ & $<0.001$ & $-9.752(5.412)$ & 0.033 & $-10.591(5.411)$ & 0.049 \\
\hline $\mathrm{HCY}<15 \mu \mathrm{mol} / \mathrm{L}$ & ref & - & ref & - & ref & - \\
\hline $\mathrm{HCY} \geq 15 \mu \mathrm{mol} / \mathrm{L}$ & $-17.791(6.029)$ & 0.004 & $-10.435(6.267)$ & 0.026 & $-11.726(4.294)$ & 0.044 \\
\hline \multicolumn{7}{|l|}{ IGI 30} \\
\hline $\mathrm{HCY}<15 \mu \mathrm{mol} / \mathrm{L}$ & ref & - & ref & - & ref & - \\
\hline $\mathrm{HCY} \geq 15 \mu \mathrm{mol} / \mathrm{L}$ & $-1.774(1.574)$ & $<0.001$ & $-1.952(0.953)$ & 0.17 & $-1.817(1.772)$ & 0.72 \\
\hline \multicolumn{7}{|l|}{ DI } \\
\hline $\mathrm{HCY}$ & $-4.407(1.170)$ & $<0.001$ & $-6.312(5.947)$ & $<0.001$ & $-6.801(5.906)$ & $<0.001$ \\
\hline $\mathrm{HCY}<15 \mu \mathrm{mol} / \mathrm{L}$ & ref & - & ref & - & ref & - \\
\hline $\mathrm{HCY} \geq 15 \mu \mathrm{mol} / \mathrm{L}$ & $-9.076(6.847)$ & 0.186 & $-7.542(5.183)$ & $<0.001$ & $-8.629(4.729)$ & 0.031 \\
\hline \multicolumn{7}{|l|}{ SUIT O h } \\
\hline $\mathrm{HCY}$ & $-0.028(0.094)$ & 0.763 & $-0.926(0.439)$ & 0.036 & $-0.777(0.436)$ & 0.016 \\
\hline $\mathrm{HCY}<15 \mu \mathrm{mol} / \mathrm{L}$ & ref & - & ref & - & ref & - \\
\hline $\mathrm{HCY} \geq 15 \mu \mathrm{mol} / \mathrm{L}$ & $-7.243(15.552)$ & 0.642 & $-6.395(3.252)$ & 0.062 & $-7.597(13.666)$ & 0.579 \\
\hline
\end{tabular}

Model 1 univariate analysis. Model 2 adjusted for age and gender. Model 3 adjusted age, gender, height, weight, waist, waist/height, BMI, FBG, 2hPBG, HbA1c, fasting insulin and C-peptide. HCY, Homocysteine; HOMA- $\beta$, Homeostasis Model Assessment- $\beta$; MBCI, Modified $\beta$ Cell Function Index; IGI 30, Insulinogenic Index 30; DI, Disposal Index; SUIT, Secretory Units of Islets in Transplantation; CPR, C-peptide immunoreactivity.

Model 2, but became statistically insignificant after adjusting for all confounders. When a HCY $<15 \mu \mathrm{mol} / \mathrm{L}$ was used as the reference, $\mathrm{HCY}$ in the $\mathrm{HCY} \geq 15 \mu \mathrm{mol} / \mathrm{L}$ group was negatively associated with HOMA- $\beta, \mathrm{MBCI}$, and SUIT at $0 \mathrm{~h}$ in all models and with IGI 30 in Model 1 . HCY in the same group was significantly inversely correlated with DI in Models 2 and 3. No statistical association was observed between $\mathrm{HCY}$ and $\mathrm{CPR}$ when $\mathrm{HCY} \geq 15 \mu \mathrm{mol} / \mathrm{L}$.

\section{Discussion}

Several important findings emerged from the present study. First, we found that HCY serum levels were positively correlated with glucose and insulin levels in T2DM patients (see Table 1 and Figure 1). In our study, T2DM patients were divided into 4 groups based on HCY quartiles, and the serum HCY concentration gradually increased from Groups Q1 to Q4. Participants in Group Q4 had significantly 
increased serum glucose, fasting, and $2 \mathrm{~h}$ PBG levels compared to those in Group Q1 $(\mathrm{P}<0.05)$. Participants in Groups Q3 and Q4 had higher HbA1c levels, which represented the average level of glucose in the past 2 months, than those in Groups Q1 and Q2 $(\mathrm{P}<0.05)$. Similar results were found in relation to fasting insulin levels, but inverse results were found in relation to fasting C-peptide levels. In relation to the IRT results, the AUCs for serum glucose and insulin levels in Group Q4 were significantly higher than the AUCs for the other three groups, while C-peptide AUC changes had an inverse tendency among the four groups $(\mathrm{P}<0.05)$. Thus, HCY was positively related to glucose metabolism in T2DM participants.

Hyperhomocysteinemia has been identified as a new significant risk factor for cardiovascular disease. Hyperhomocysteinemia involves different mechanisms, including the stimulation of smooth muscle cell proliferation, vascular endothelium damage, and enhanced thrombosis activation (19). Normally, serum HCY concentration is kept low by the continuous turnover to either cysteine or methionine, and it is affected by some risk factors related to genetic variations (a default in cystatin B synthetase or 5,10-methylene tetrahydrofolate reductase), poor diet (a lack of folate, vitamin B12, or vitamin B6), impaired kidney function, certain carcinomas, hypothyroidism, certain medications, coffee consumption, smoking and drinking (20).

Serum HCY levels can be elevated in T2DM patients, and have been reported to be associated with T2DM complications. HCY can act as a determinant of left ventricular ejection fraction (LVEF) in patients with diabetes. One study of 409 T2DM patients who underwent stress myocardial perfusion imaging showed that HCY levels were significantly associated with low levels of LVEF in the univariate analyses, and were independent of age, gender, smoking, blood pressure, renal function, folates, vitamin B12, lipid parameters, and hepatic enzymes (21). Other studies have shown increases in plasma HCY concentration in proliferative diabetic retinopathy, diabetic nephropathy, and diabetic peripheral neuropathy patients (22-24). Ala showed higher HCY levels in T2DM patients, and that HCY levels worsened with increased insulin resistance, dyslipidaemia, and poor glucose control (11). Atsushi Araki et al. researched the association between plasma HCY and serum interleukin (IL)-6 levels, and found that the activation of innate immunity was involved in the pathogenesis of arteriosclerosis in T2DM patients (25).
Another main finding of this study was the significant independent association between the insulin releasing function of pancreatic islet beta cells and serum HCY levels. This association indicates a potential link between the pathogenesis of T2DM and hyperhomocysteinemia. Pancreatic beta-cell function decreases from the clinical onset among patients in both categories of diabetes mellitus, and is always accompanied by a corresponding deterioration in the glycemic situation. Unlike type 1 diabetes, the reduced beta-cell function in T2DM is mainly associated with insulin resistance, which is often accompanied by hyperlipidemia and obesity. The loss of beta-cell function is accompanied by the development of T2DM and may occur gradually before a diagnosis. A $40 \%$ reduction in beta-cell mass has been reported in obese individuals with impaired fasting glucose, and a $60 \%$ reduction has been observed in overt T2DM patients (26). Thus, impairments in beta-cell function occur before the onset of T2DM.

The factors inducing or aggravating the progressive reduction of beta-cell function are hotly debated worldwide. Hyperglycemia can result in glucotoxicity, which has detrimental effects on insulin secretion and synthesis (27). Prolonged exposure to increased glucose levels has been shown to alter the expression of several insulin-generation related genes. Consequently, pancreatic islet beta cells secrete more insulin and need to synthesize more proinsulin in endoplasmic reticulum (ER), which leads to cellular stress (28). Additionally, increasing metabolic flux rushes into the mitochondria where the excessive production of reactive oxygen species results in oxidative stress and ultimately induces beta-cell dysfunction or even death (29). Due to the relationship between ER and oxidative stress, inflammation has been shown to participate in the process of gradual beta-cell function deterioration in T2DM patients (30). Proinflammatory cytokines and chemokines, such as tumor necrosis factor $\alpha$, monocyte chemoattractant protein-1 (MCP-1), and IL6, enhance production, and activates and attracts macrophages to the pancreas (30). Conversely, adipokines secreted from adipose tissues have local and systemic effects on the chronic inflammation process in adipocytes (5).

$\mathrm{HCY}$ is a potential proinflammatory and pro-oxidative compound that stimulates inflammatory transcriptional signaling pathways (31). Hyperhomocysteinemia can induce ER stress, activate mitogen-activated protein kinase, promote proinflammatory cytokine production, and facilitate macrophage infiltration by activating the c-Jun $\mathrm{N}$-terminal kinase pathway $(32,33)$. HCY has the ability to 
initiate the progression of vascular diseases by inducing the expression and secretion of inflammatory cytokines, such as IL-8, and MCP-1 (34). In addition, HCY has been reported to have the ability to harm beta-cell glucose metabolism, insulin secretory responsiveness, and beta-cell viability. HCY exerts detrimental effects on redox-cycling reactions, which explains the decline in the viability of insulinsecreting cells, which in turn leads to a reduced glucokinase phosphorylating ability, diminished insulin secretory responsiveness, and cell apoptosis (35). Consequently, hyperhomocysteinemia is considered a consequence of low-grade systemic inflammation, which is involved in the pathogenesis of T2DM. Thus, we hypothesized that the inflammation process and reaction may be the link between plasma HCY and pancreatic islet beta-cell function.

The hyperglycemic clamp is considered the goldstandard for evaluating insulin secretion and resistance; however, it is inconvenient because of it has high costs, is time consuming, and requires complicated technical skills. Thus, a simpler method, called the OGTT, was manipulated for the diagnosis of T2DM, and some surrogate markers derived from IRT were applied to evaluate beta-cell function. These surrogate markers included HOMA- $\beta$, MBCI, DI, CPR, IGI and SUIT, which we calculated and compared among groups in our study. These paraments were used to compare insulin sensitivity and the beta-cell secretion of insulin. We calculated these paraments from the serum data and compared them among the four groups. These indexes decreased as the group grade increased, which indicated that the insulin secretion capability of pancreatic beta cells were impaired as HCY levels increased. HOMA- $\beta$, MBCI, DI, CPR, IGI 30 , and SUIT levels at $0 \mathrm{~h}$ were negatively and linearly correlated with serum HCY levels $\left(\mathrm{R}^{2}=0.539,0.569,0.500,0.676,0.579\right.$, and 0.588, respectively; $\mathrm{P}<0.05)$. Thus, serum HCY can be regarded as a candidate for the indication of pancreatic islet beta-cell function.

Third, our multiple linear-regression analysis model showed that HOMA- $\beta$, MBCI, DI, CPR, and SUIT levels at $0 \mathrm{~h}$ were significantly negatively associated with $\mathrm{HCY}$ levels in Model 2, but there was no relationship between CPR and HCY in Model 3. Next, when HCY concentration was $\geq 15 \mu \mathrm{mol} / \mathrm{L}$, HOMA- $\beta$, MBCI, and SUIT levels at $0 \mathrm{~h}$ and IGI 30 were significantly inversely correlated with HCY levels in Model 1; however, the relationship between IGI 30 and HCY was not found in Models 2 and 3, but a relationship between DI and HCY was found in Models 2 and 3. After taking many confounders into consideration, our results showed that HCY is representative of HOMA- $\beta$, MBCI, DI, and SUIT at $0 \mathrm{~h}$, which indicated the function of pancreatic islet beta cells.

\section{Conclusions}

In our study, plasma HCY levels were significantly correlated with pancreatic islet beta-cell function, and this association was independent of many confounders, such as age, gender, FBG, 2 h PBG, BMI, HbAlc, fasting insulin, and C-peptide. Thus, plasma HCY levels are a good predictor of functional alterations in the insulin release of beta cells in the pancreas.

\section{Acknowledgments}

The authors would like to thank all those who enrolled in our study for their participation.

Funding: This work was supported by Shanghai Natural Science Foundation (19ZR1447500), Scientific Program of Shanghai Pudong Hospital (YJRCJJ201808,YJRCJJ201811), Talents Training Program of Pudong Hospital affiliated to Fudan University (PJ202001), Science and Technology Development Fund of Shanghai Pudong New Area (PKJ2019-Y37), the Project of Key Medical Discipline of Pudong Hospital of Fudan University (Zdxk2020-11), the Project of Key Medical Specialty and Treatment Center of Pudong Hospital of Fudan University (Zdzk2020-24) and the Outstanding Clinical Discipline Project of Shanghai Pudong (PWYgy-2018-08).

\section{Footnote}

Reporting Checklist: The authors have completed the STROBR reporting checklist. Available at https://dx.doi. org/10.21037/apm-21-1671

Data Sharing Statement: Available at https://dx.doi. org/10.21037/apm-21-1671

Conflicts of Interest: All authors have completed the ICMJE uniform disclosure form (available at https://dx.doi. org/10.21037/apm-21-1671). The authors have no conflicts of interest to declare.

Ethical Statement: The authors are accountable for all aspects of the work in ensuring that questions related to the accuracy or integrity of any part of the work are 
appropriately investigated and resolved. This study was conducted in accordance with the principles of the Declaration of Helsinki (as revised in 2013). This study was approved by ethics board of Shanghai Pudong Hospital (No.: wz-009). Informed consent was obtained from all individual participants included in the study. Consent to publish was also obtained from all participants in this study.

Open Access Statement: This is an Open Access article distributed in accordance with the Creative Commons Attribution-NonCommercial-NoDerivs 4.0 International License (CC BY-NC-ND 4.0), which permits the noncommercial replication and distribution of the article with the strict proviso that no changes or edits are made and the original work is properly cited (including links to both the formal publication through the relevant DOI and the license). See: https://creativecommons.org/licenses/by-nc-nd/4.0/.

\section{References}

1. Greenhill C. Defining genetic risk of T2DM. Nat Rev Endocrinol 2019;15:438.

2. Wang L, Gao P, Zhang M, et al. Prevalence and Ethnic Pattern of Diabetes and Prediabetes in China in 2013. JAMA 2017;317:2515-23.

3. $\mathrm{Xu} \mathrm{Y,} \mathrm{Wang} \mathrm{L,} \mathrm{He} \mathrm{J,} \mathrm{et} \mathrm{al.} \mathrm{Prevalence} \mathrm{and} \mathrm{control} \mathrm{of}$ diabetes in Chinese adults. JAMA 2013;310:948-59.

4. Bakhti M, Bottcher A, Lickert H. Modelling the endocrine pancreas in health and disease. Nat Rev Endocrinol 2019;15:155-71.

5. Cernea S, Dobreanu M. Diabetes and beta cell function: from mechanisms to evaluation and clinical implications. Biochem Med (Zagreb) 2013;23:266-80

6. Muniyappa R, Lee S, Chen H and Quon MJ. Current approaches for assessing insulin sensitivity and resistance in vivo: advantages, limitations, and appropriate usage. Am J Physiol Endocrinol Metab 2008;294:E15-E26.

7. Hu Y, Xu Y, Wang G. Homocysteine Levels are Associated with Endothelial Function in Newly Diagnosed Type 2 Diabetes Mellitus Patients. Metab Syndr Relat Disord 2019;17:323-7.

8. Yu C, Wang J, Wang F, et al. Inverse association between plasma homocysteine concentrations and type 2 diabetes mellitus among a middle-aged and elderly Chinese population. Nutr Metab Cardiovasc Dis 2018;28:278-84.

9. Luo JL, Chien KL, Hsu HC, et al. Association between plasma homocysteine concentration and the risk of allcause death in adults with diastolic dysfunction in a community: A 13-year cohort study. Medicine (Baltimore) 2017;96:e6716.

10. Sonoda M, Shoji T, Kuwamura Y, et al. Plasma homocysteine and cerebral small vessel disease as possible mediators between kidney and cognitive functions in patients with diabetes mellitus. Sci Rep 2017;7:4382.

11. Ala OA, Akintunde AA, Ikem RT, et al. Association between insulin resistance and total plasma homocysteine levels in type 2 diabetes mellitus patients in south west Nigeria. Diabetes Metab Syndr 2017;11 Suppl 2:S803-S809.

12. Alberti KG, Zimmet PZ. Definition, diagnosis and classification of diabetes mellitus and its complications. Part 1: diagnosis and classification of diabetes mellitus provisional report of a WHO consultation. Diabet Med. 1998;15:539-53.

13. Matthews DR, Hosker JP, Rudenski AS, et al. Homeostasis model assessment: insulin resistance and beta-cell function from fasting plasma glucose and insulin concentrations in man. Diabetologia 1985;28:412-9.

14. Meng LH, Huang Y, Zhou J, et al. Use of First-phase Insulin Secretion in Early Diagnosis of Thyroid Diabetes and Type 2 Diabetes Mellitus. Chin Med J (Engl) 2017;130:798-804.

15. Lee DY, Yoo MG, Kim HJ, et al. Association between alcohol consumption pattern and the incidence risk of type 2 diabetes in Korean men: A 12-years follow-up study. Sci Rep 2017;7:7322.

16. Yamada Y, Fukuda K, Fujimoto S, et al. SUIT, secretory units of islets in transplantation: An index for therapeutic management of islet transplanted patients and its application to type 2 diabetes. Diabetes Res Clin Pract 2006;74:222-6.

17. Kubota A, Matsuba I, Saito T, et al. Secretory units of islets in transplantation index is a useful clinical marker to evaluate the efficacy of sitagliptin in treatment of type 2 diabetes mellitus. J Diabetes Investig 2011;2:377-80.

18. Funakoshi S, Fujimoto S, Hamasaki A, et al. Analysis of factors influencing pancreatic beta-cell function in Japanese patients with type 2 diabetes: association with body mass index and duration of diabetic exposure. Diabetes Res Clin Pract 2008;82:353-8.

19. Keller AC, Klawitter J, Hildreth KL, et al. Elevated plasma homocysteine and cysteine are associated with endothelial dysfunction across menopausal stages in healthy women. J Appl Physiol (1985) 2019;126:1533-40.

20. Björck J, Hellgren M, Rastam L, et al. Associations between serum insulin and homocysteine in a Swedish 
population-a potential link between the metabolic syndrome and hyperhomocysteinemia: the Skaraborg project. Metabolism 2006;5 5:1007-13.

21. Badiou S, Dupuy AM, Jaussent I, et al. Homocysteine as a determinant of left ventricular ejection fraction in patients with diabetes. Clin Chem Lab Med 2012;50:1099-106.

22. Aydemir O, Turkcuoglu P, Guler M, et al. Plasma and vitreous homocysteine concentrations in patients with proliferative diabetic retinopathy. Retina 2008;28:741-3.

23. Wang T, Wang Q, Wang Z, et al. Diagnostic value of the combined measurement of serum hcy, serum cys $\mathrm{C}$, and urinary microalbumin in type 2 diabetes mellitus with early complicating diabetic nephropathy. ISRN Endocrinol 2013;2013:407452.

24. Zheng LQ, Zhang HL, Guan ZH, et al. Elevated serum homocysteine level in the development of diabetic peripheral neuropathy. Genet Mol Res 2015;14:15365-75.

25. Araki A, Hosoi T, Orimo H, et al. Association of plasma homocysteine with serum interleukin-6 and C-peptide levels in patients with type 2 diabetes. Metabolism 2005;54:809-14.

26. Wajchenberg BL. beta-cell failure in diabetes and preservation by clinical treatment. Endocr Rev 2007;28:187-218.

27. Haythorne E, Rohm M, van de Bunt M, et al. Diabetes causes marked inhibition of mitochondrial metabolism in pancreatic beta-cells. Nat Commun 2019;10:2474.

28. Lees JA, Messa M, Sun EW, et al. Lipid transport by TMEM24 at ER-plasma membrane contacts regulates pulsatile insulin secretion. Science 2017;355:eaah6171.

Cite this article as: Yuan X, Ding S, Zhou L, Wen S, Du A, Diao J. Association between plasma homocysteine levels and pancreatic islet beta-cell function in the patients with type 2 diabetes mellitus: a cross-sectional study from China. Ann Palliat Med 2021;10(7):8169-8179. doi: 10.21037/apm-21-1671
29. Fu J, Cui Q, Yang B, et al. The impairment of glucosestimulated insulin secretion in pancreatic beta-cells caused by prolonged glucotoxicity and lipotoxicity is associated with elevated adaptive antioxidant response. Food Chem Toxicol 2017;100:161-7.

30. Nadeem A, Mumtaz S, Naveed AK, et al. Gene-gene, gene-environment, gene-nutrient interactions and single nucleotide polymorphisms of inflammatory cytokines. World J Diabetes 2015;6:642-7.

31. Qi X, Zhang B, Zhao Y, et al. Hyperhomocysteinemia Promotes Insulin Resistance and Adipose Tissue Inflammation in PCOS Mice Through Modulating M2 Macrophage Polarization via Estrogen Suppression. Endocrinology 2017;158:1181-93.

32. Li Y, Zhang H, Jiang C, et al. Hyperhomocysteinemia promotes insulin resistance by inducing endoplasmic reticulum stress in adipose tissue. J Biol Chem 2013;288:9583-92.

33. Ingram AJ, Krepinsky JC, James L, et al. Activation of mesangial cell MAPK in response to homocysteine. Kidney Int 2004;66:733-45.

34. Poddar R, Sivasubramanian N, DiBello PM, et al. Homocysteine induces expression and secretion of monocyte chemoattractant protein-1 and interleukin-8 in human aortic endothelial cells: implications for vascular disease. Circulation 2001;103:2717-23

35. Scullion SM, Gurgul-Convey E, Elsner M, et al. Enhancement of homocysteine toxicity to insulinsecreting BRIN-BD11 cells in combination with alloxan. J Endocrinol 2012;214:233-8. Erratum in: J Endocrinol 2012;214:445-6. 